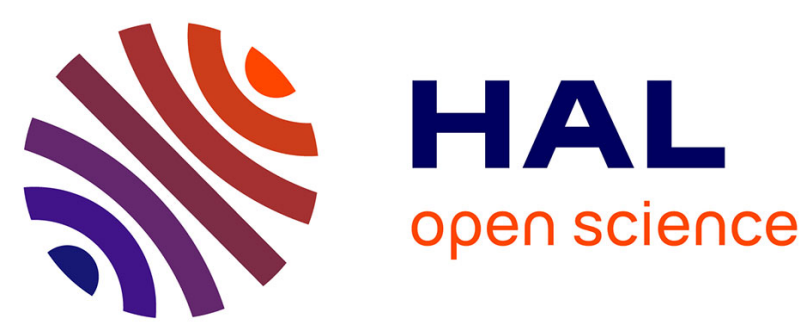

\title{
A PROBABILISTIC TWO-SCALE MODEL FOR HIGH CYCLE FATIGUE LIFE PREDICTIONS
}

Cédric Doudard, Sylvain Calloch, Philippe Cugy, André Galtier, François Hild

\section{To cite this version:}

Cédric Doudard, Sylvain Calloch, Philippe Cugy, André Galtier, François Hild. A PROBABILISTIC TWO-SCALE MODEL FOR HIGH CYCLE FATIGUE LIFE PREDICTIONS. Fatigue and Fracture of Engineering Materials and Structures, 2005, 28, pp.279-288. 10.1111/j.1460-2695.2005.00854.x . hal-00322496

\section{HAL Id: hal-00322496 https://hal.science/hal-00322496}

Submitted on 17 Sep 2008

HAL is a multi-disciplinary open access archive for the deposit and dissemination of scientific research documents, whether they are published or not. The documents may come from teaching and research institutions in France or abroad, or from public or private research centers.
L'archive ouverte pluridisciplinaire HAL, est destinée au dépôt et à la diffusion de documents scientifiques de niveau recherche, publiés ou non, émanant des établissements d'enseignement et de recherche français ou étrangers, des laboratoires publics ou privés. 


\author{
A PROBABILISTIC TWO-SCALE MODEL \\ FOR HIGH CYCLE FATIGUE LIFE PREDICTIONS \\ C. DOUDARD, ${ }^{* 1}$ S. CALLOCH, ${ }^{*}$ P. CUGY, ${ }^{* *}$ A. GALTIER ${ }^{* *}$ and F. HILD ${ }^{*}$ \\ *LMT-CACHAN, ENS de CACHAN/CNRS-UMR 8535/Université Paris 6 \\ 61 avenue du Président Wilson, F-94235 Cachan Cedex, France \\ **IRSID, groupe ARCELOR, voie romaine BP 30320, F-57283 Maizières-lès-Metz Cedex, France
}

\begin{abstract}
It is proposed to develop and identify a probabilistic two-scale model for HCF that accounts for the failure of samples but also for the thermal effects during cyclic loadings in a unified framework. The probabilistic model is based on a Poisson point process. Within the weakest link theory, the model corresponds to a Weibull law for the fatigue limits. The thermal effects can be described if one considers the same hypotheses apart from the weakest link assumption. A method of identification is proposed and uses temperature measurements to identify the scatter in an $\mathrm{S} / \mathrm{N}$ curve. The validation of the model is obtained by predicting $\mathrm{S} / \mathrm{N}$ curves for different effective volumes of a dual-phase steel.
\end{abstract}

Keywords Fatigue limits; Weibull model; Microplasticity; Thermomechanics.

${ }^{1}$ Corresponding author: Fax: +33 1474022 40, E-mail: doudard@lmt.ens-cachan.fr 


\section{Introduction}

The industry is one of the domains that need good design procedures to ensure the reliability of structures $[1,2]$. Since fracture of structures is often due to fatigue and fatigue data are usually scattered, probabilistic approaches have been developed in High Cycle Fatigue (HCF) lifing [1, 3, 4]. With these approaches, the scatter of fatigue data can be described, as well as the dependence of fatigue limits with the loaded volume and the type of loading by introducing the so-called effective volume [5]. Consequently, the fatigue limits depend on material properties as well as the effective volume. The identification of probabilistic models is often based on numerous experimental fatigue tests to properly evaluate the scatter [6]. The predictive capability of probabilistic models can be improved by identifying the origin of the scatter (e.g., size distributions of microshrinkage cavities in nodular graphite cast iron [7]). The knowledge of the defect distributions allows one to predict the reliability of structures with different distributions [8]. In the present paper, another identification route is followed to determine the scatter of experimental fatigue results by assuming that it is induced by a heterogeneous microplastic activity.

Some authors [9-14] have worked on an estimation of the mean fatigue limit based upon temperature measurements. This method consists in observing the thermal effect during cyclic loadings. It has the advantage of being performed in shorter time compared with traditional HCF tests. A good correlation can be obtained between the inception of a temperature increase and the mean fatigue limit. However, this method gives access to a single value of the fatigue limit, whereas there is a whole set of fatigue limits associated to different failure probabilities. If a probabilistic approach useful for HCF life prediction is considered, then the analysis of the temperature measurements cannot be used in a classical way and needs to be revisited. It will be used to identify parameters relevant to a probabilistic model to describe the initiation stage in HCF.

The present paper is concerned with the derivation and identification of a probabilistic twoscale model for HCF that accounts for the failure of samples but also for the thermal effects during cyclic loadings in a unified framework. A two-scale model, which is based on the approach 
proposed by Lemaitre et al. $[15,16]$, is used. It is assumed that HCF damage occurs at the microscopic scale and is caused by microplasticity that has a weak effect on the behavior of the material at the macroscopic scale. The development of the model is presented in two successive stages. In the first one, a deterministic viewpoint is chosen to show that the thermal effects can be accounted for by integrating the heat equation in which the microplastic dissipation is included. In view of a single microplastic hardening law, the empirical method proposed to estimate quickly the mean fatigue limits $[9,12-14]$ can be described to determine a deterministic (i.e., mean) fatigue limit. The model is then extended by introducing a random yield stress distribution at the microscopic scale. The new model describes more closely the thermal effects than the first one. With this approach, the scatter can be determined but not necessarily the mean fatigue limit of a sample. An identification method of the scatter is proposed. It is based on the analysis of the thermal effects for the scatter and is applied on a dual-phase steel. This steel is used in the automotive industry that requires the knowledge of the fatigue properties and their scatter [17-25]. In particular, the change of the fatigue limit is described by using the effective volume concept. A first validation of the model is shown by predicting the scatter of Wöhler curves of tensile tests (fully reversed axial loading tests). A second validation is proposed by comparing the experimental results in alternate bending to the model predictions.

\section{Behavior of a dual-phase steel under cyclic loadings}

The material studied herein is a ferrite-martensite dual-phase steel grade (around $15 \mathrm{wt} \%$ of martensite, Arcelor designation: DP600) in its cold-rolled state. The chemical composition of the studied dual-phase steel is given in Table 1. This steel offers a better combination of strength and ductility than other conventional steels. The product ultimate tensile strength $\times$ elongation (in \%) at failure for classical steels is generally of the order of $12 \mathrm{GPa}$ whereas dual-phase steels reach $16 \mathrm{GPa}$. The mechanical properties obtained from monotonic tensile tests on samples in the rolling direction are given in Table 2. This steel has a good capacity of straining and hardening. That is 
why the dual-phase steels are used in the automotive industry where metal forming processes need these types of properties.

To evaluate the fatigue properties of dual-phase steels, temperature measurements can be used. They consist in applying successive series of 3000 cycles (Fig. 1a) for different increasing stress amplitudes $\Sigma_{0}$ (Fig. 1b). For each stress amplitude, the change of the temperature variation $\theta=T-T_{0}$ (where $T$ is the current temperature of the sample during the test measured by a thermocouple and $\mathrm{T}_{0}$ the initial value) is recorded (Fig. 1c). In the following developments, it is assumed that the temperature field is homogeneous in the sample. This hypothesis cannot always be made [26] and the analysis becomes more involved to identify dissipation sources with a sample or a structure. The mean temperature becomes stable after about 1000 cycles and equals $\bar{\theta}\left(\Sigma_{0}\right)$. Figure 1d shows the change of the steady-state mean temperature $\bar{\theta}\left(\Sigma_{0}\right)$ with the stress amplitude for a dual-phase steel for two different tests. One can see that the information is reproducible. This result has been obtained by different authors $[13,14]$. Furthermore, $\bar{\theta}\left(\Sigma_{0}\right)$ suddenly increases as the stress level is close to the fatigue limit of the material. This change of regime can be explained by the occurrence of the first slip bands on the surface [14]. In the next sections, two different models are introduced to relate the change of the mean temperature during series of cyclic loadings to the fatigue properties of the material.

\section{A deterministic two-scale model}

The two-scale model used herein has been initially developed by Lemaitre and Doghri [15], and then extended by Lemaitre et al. [16] in a deterministic way. It is based on the hypothesis that HCF damage is localized at the microscopic scale, whose dimensions are smaller than those of the representative volume element (RVE) of volume $\mathrm{V}_{\mathrm{RVE}}$ associated to the mesoscopic scale. Consequently, two phases are considered in the model (Fig. 2). The first one is an inclusion of volume $\mathrm{V}_{0}$ accounting for a set of grains where local plasticity occurs; the second one is the surrounding matrix describing the other grains. The two phases are assumed to have the same 
elastic behavior and the yield stress of the elasto-plastic inclusion $\sigma_{\mathrm{y}}^{\mu}$ is less than that of the surrounding matrix that remains elastic.

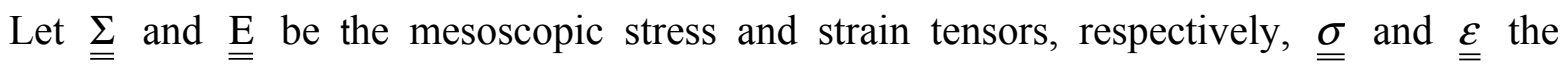
microscopic stress and strain tensors in the inclusions, respectively. An additive decomposition of strain with an elastic part ${\underset{\varepsilon}{\mathrm{e}}}^{\mathrm{e}}$ and a plastic part $\underset{\underline{\varepsilon}}{\mathrm{p}}$ is assumed for the inclusion

$$
\underline{\underline{\varepsilon}}=\underline{\underline{\varepsilon}}^{\mathrm{e}}+\underline{\underline{\varepsilon}}^{\mathrm{p}}
$$

A linear kinematic hardening is considered in this work. It follows that the back stress $\underline{\underline{X}}$ can be related to the plastic strain tensor $\underset{=}{\underline{\varepsilon}}$ in the inclusion by [27]

$$
\underline{\underline{\mathrm{X}}}=\frac{2}{3} \mathrm{C} \underline{\underline{\dot{\varepsilon}}}^{\mathrm{p}}
$$

where $\mathrm{C}$ is a parameter depending on the material, and a dotted variable corresponds to its first derivative with respect to time. A normality rule is assumed for the plasticity model

$$
\underline{\dot{\varepsilon}}^{\mathrm{p}}=\dot{\lambda} \frac{\partial \mathrm{f}}{\partial \underline{\underline{S}}}
$$

with the usual Kuhn-Tucker conditions, $\underset{\underline{S}}{=} \underline{\underline{\sigma}}-\frac{1}{3} \operatorname{trace}(\underline{\underline{\sigma}}) \underline{\underline{\mathrm{I}}}$ is the deviatoric stress tensor, $\underline{\underline{\mathrm{I}}}$ the unit second order tensor, $\dot{\lambda}$ the plastic multiplier and $f$ the yield surface

$$
\mathrm{f}=\mathrm{J}_{2}(\underline{\underline{\mathrm{S}}}-\underline{\underline{X}})-\sigma_{\mathrm{y}}^{\mu} \leq 0
$$

where $\mathrm{J}_{2}$ is the second stress invariant, i.e., $\mathrm{J}_{2}(\underline{\underline{S}}-\underline{\underline{X}})=\sqrt{\frac{3}{2}(\underline{\underline{S}}-\underline{\underline{X}}):(\underline{\underline{S}}-\underline{\underline{X}})}$, and ':' the tensorial product contracted with respect to two indices. The microscopic stresses are evaluated from the mesoscopic stresses by means of a law of localization. This law is obtained by a homogenization procedure $[28,29]$

$$
\underline{\underline{\sigma}}=\underline{\underline{\Sigma}}-2 \mu(1-\beta)\left(\underline{\underline{\varepsilon}}^{p}\right),
$$


with $\beta=\frac{2(4-5 v)}{15(1-v)}$ given by the Eshelby analysis of a spherical inclusion [30], $\mu$ and $v$, the shear modulus and the Poisson's ratio of the dual-phase steel, respectively.

The concepts of continuum thermodynamics $[27,31]$ are used to analyze the temperature measurements. At each instant $t$, the thermodynamic state of each RVE is characterized by state variables. In the present case, three state variables are used, namely, $\mathrm{T}$ the absolute temperature (or $\left.\theta=\mathrm{T}-\mathrm{T}_{0}\right), \underline{\underline{\varepsilon}}^{\mathrm{e}}$ and $\underline{\underline{\varepsilon}}^{\mathrm{p}}$. The specific Helmholtz free energy of the RVE $\Psi$ is defined by the following relationship

$$
\Psi=\Psi_{\text {mat }}\left(1-f_{\mathrm{v}}\right)+\Psi_{\text {in }} f_{\mathrm{v}},
$$

where $f_{v}=V_{0} / V_{R V E}$ is the volume fraction of the inclusion in the RVE, $\Psi_{\text {mat }}$ and $\Psi_{\text {in }}$ are the free energy densities of the matrix and the inclusion, respectively

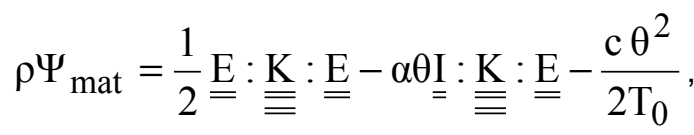

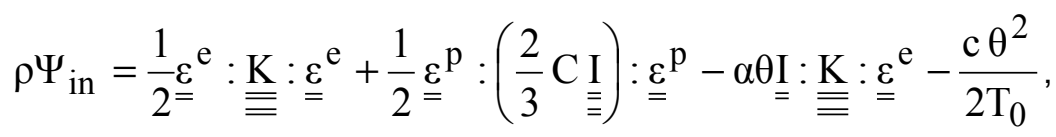

where $\underline{\underline{\underline{\underline{K}}}}$ is the elastic tensor, $\rho$ the mass density, c the specific heat capacity, $\underset{\equiv}{I}$ the unit fourth order tensor, and $\alpha$ the coefficient of thermal expansion. In Eqn. (7), the free energy characterizes a thermo-elastic behavior for which the first term is the elastic or recoverable contribution, the second corresponds to the thermo-elastic coupling and the third to the temperature contribution associated to temperature variations that remain small (with $\theta<10 \mathrm{~K}$ ). In the right-hand side of Eqn. (8), in addition to the previous contributions, the second term corresponds to the stored energy caused by the hardening of the material at the scale of the inclusion.

By application of the first law of thermodynamics, the external power $\Pi$ can be written as

$$
\Pi=\left(1-\mathrm{f}_{\mathrm{v}}\right) \underline{\underline{\Sigma}}: \underline{\underline{\dot{\mathrm{E}}}}+\mathrm{f}_{\mathrm{v}} \underline{\underline{\sigma}}_{\underline{\underline{\dot{\varepsilon}}}}^{\mathrm{e}}+\mathrm{f}_{\mathrm{v}}\left(\underline{\underline{\sigma}}^{-\underline{\underline{X}}}\right): \underline{\dot{\varepsilon}}^{\mathrm{p}}+\mathrm{f}_{\mathrm{v}} \underline{\underline{X}}: \underline{\underline{\dot{\varepsilon}}}^{\mathrm{p}}
$$


where $\left(1-\mathrm{f}_{\mathrm{V}}\right) \underline{\underline{\Sigma}}: \underline{\underline{\mathrm{E}}}$ and $\mathrm{f}_{\mathrm{V}} \underline{\underline{\sigma}}: \stackrel{\dot{\varepsilon}}{\mathrm{e}}^{\mathrm{e}}$ are the recoverable elastic power, $\mathrm{f}_{\mathrm{V}} \underline{\underline{\mathrm{X}}}: \dot{\dot{\varepsilon}}^{\mathrm{p}}$ the plastic power and $\mathrm{f}_{\mathrm{V}}(\underline{\underline{\sigma}}-\underline{\underline{X}}): \dot{\underline{\varepsilon}}^{\mathrm{p}}$ the dissipated power. The dissipated power $\Delta$ describes, among other things, the losses in heat during the motion of dislocations and is given by

$$
\Delta=\mathrm{f}_{\mathrm{v}}(\underline{\underline{\sigma}}-\underline{\underline{\mathrm{X}}}): \underline{\underline{\dot{\varepsilon}}}^{\mathrm{p}}=\mathrm{f}_{\mathrm{v}}(\underline{\underline{\sigma}}-\underline{\underline{\mathrm{X}}}): \dot{\lambda} \frac{\partial \mathrm{f}}{\partial \underline{\underline{\sigma}}} .
$$

The plastic multiplier $\dot{\lambda}$ is obtained from the consistency condition

$$
\dot{\mathrm{f}}=\frac{\partial \mathrm{f}}{\partial \underline{\underline{\sigma}}}: \underline{\underline{\dot{\sigma}}}+\frac{\partial \mathrm{f}}{\partial \underline{\underline{X}}}: \underline{\underline{\dot{X}}}=0
$$

By using the law of localization (5) and the kinematic hardening kinetics (2), Eqn. (11) can be rewritten as

$$
\frac{\partial f}{\partial \underline{\underline{\sigma}}}:\left[\underline{\dot{\Sigma}}_{=}-2 \mu(1-\beta) \underline{\underline{\dot{\varepsilon}}}^{\mathrm{p}}-\frac{2}{3} \mathrm{C} \dot{\underline{\varepsilon}}^{\mathrm{p}}\right]=0 .
$$

Consequently, one can deduce the following relationship by using the normality rule (3) with the hardening modulus $\mathrm{h}=\mathrm{C}+3 \mu(1-\beta)$

$$
\dot{\lambda}=\frac{\mathrm{H}(\mathrm{f})}{\mathrm{h}} \frac{\partial \mathrm{f}}{\partial \underline{\underline{\sigma}}}: \dot{\underline{\Sigma}}
$$

where $\mathrm{H}$ is the Heaviside step function (i.e., $\mathrm{H}(\mathrm{f})=0$ if $\mathrm{f}<0$ and $\mathrm{H}(\mathrm{f})=1$ if $\mathrm{f}=0$ ). The dissipated energy density $\mathrm{D}$ for a loading cycle becomes

$$
\mathrm{D}=\int_{\text {cycle }} \mathrm{f}_{\mathrm{v}} \frac{\mathrm{H}(\mathrm{f})}{\mathrm{h}}\left(\frac{\partial \mathrm{f}}{\partial \underline{\underline{\sigma}}}: \underline{\underline{\dot{\Sigma}}}\right)\left[(\underline{\underline{\sigma}}-\underline{\underline{X}}): \frac{\partial \mathrm{f}}{\partial \underline{\underline{\sigma}}}\right] \mathrm{dt} .
$$

The integration of this last equation yields

$$
\mathrm{D}=\frac{4 \mathrm{f}_{\mathrm{v}} \sigma_{\mathrm{y}}^{\mu}}{\mathrm{h}}\left\langle\Sigma_{0}-\sigma_{\mathrm{y}}^{\mu}\right\rangle
$$

where $\langle$.$\rangle are the Macauley brackets (i.e. positive part of '.'). The stored power \Pi_{s}$ is expressed as

$$
\Pi_{\mathrm{s}}=\mathrm{f}_{\mathrm{v}} \underline{\underline{\underline{X}}}: \underline{\underline{\dot{\varepsilon}}}^{\mathrm{p}}=\mathrm{f}_{\mathrm{v}} \frac{2}{3} \mathrm{C} \underline{\underline{X}}: \underline{\underline{\dot{X}}}
$$


so that the stored energy for one cycle vanishes. Consequently, the only energy that accumulates during the cycles is the dissipated part. An energetic initiation criterion is chosen by assuming for the material the existence of a critical dissipated energy $\left(E_{c}\right)$ above which failure occurs. This type of hypothesis was also made by Charkaluk et al. [32]. It can be noted that it is assumed that initiation is the more time consuming stage in the present study so that failure is mainly described by the initiation stage. For each cycle, the dissipated energy is constant. Consequently, the number of cycles to failure $\mathrm{N}$ is related to $\mathrm{D}$ and $\mathrm{E}_{\mathrm{c}}$ by

$$
\mathrm{ND}=\mathrm{E}_{\mathrm{c}}
$$

so that the number of cycles to failure can be linked to the stress level $\Sigma_{0}$ and the microscopic yield stress $\sigma_{y}^{\mu}$ through Eqn. (15) by

$$
\mathrm{N}=\frac{\mathrm{A}}{\left\langle\Sigma_{0}-\sigma_{\mathrm{y}}^{\mu}\right\rangle \sigma_{\mathrm{y}}^{\mu}},
$$

where $\mathrm{A}=\mathrm{hE}_{\mathrm{c}} / 4 \mathrm{f}_{v}$ is a parameter depending on the considered material. Let $\sigma_{y}^{\mu}=\bar{\Sigma}_{\infty}$ denote the mean fatigue limit [16], Fig. 3 shows that the model agrees well with experimental results by using a relevant couple of parameters (A, $\sigma_{y}^{\mu}$ ). Equation (18) corresponds to Stromeyer's law [33]. By using the thermodynamic considerations developed herein, it can be shown that the parameters of Stromeyer's law can be related to those of a microplasticity model.

The previous results are now used to analyze the heat transfer induced by the intrinsic dissipation D. The heat equation is deduced from the two first principles of thermodynamics. Let us assume that the convective terms of the material time derivative and the coupling between temperature and the hardening variable are negligible, and that the external heat supply $\mathrm{r}$ is timeindependent. The local heat conduction equation is given by [26]

$$
\rho c \dot{\theta}-\mathrm{k} \Delta \theta=\mathrm{D}+\mathrm{T} \rho \frac{\partial^{2} \Psi}{\partial T \partial \underline{\underline{\varepsilon}}}: \dot{\underline{\varepsilon}}^{\mathrm{e}}=\rho \mathrm{cS} \mathrm{t},
$$


where $\rho c \dot{\theta}$ denotes the absorption heat capacity and $\mathrm{k} \Delta \theta=-\operatorname{div}(\overrightarrow{\mathrm{q}})$ denotes the losses by conduction, with $\mathrm{k}$ the thermal conductivity, $\overrightarrow{\mathrm{q}}$ the heat influx vector and $\mathrm{S}_{\mathrm{t}}$ the heat source depending on the thermoelastic coupling and the intrinsic dissipation. For small temperature variations $(\theta<10 \mathrm{~K}), \mathrm{k}$ and $\mathrm{c}$ are independent of the temperature. If the temperature is homogeneous, an analysis of the thermal boundary conditions with the surrounding air and with the grips of the testing machine (Fig. 4) gives the following relationship for the mean losses by conduction [34]

$$
\frac{1}{\mathrm{~V}} \int \operatorname{div}(\overrightarrow{\mathrm{q}}) \mathrm{dV}=\left(\frac{2 \mathrm{~h}_{1}(\mathrm{e}+1)}{\mathrm{el}}+\frac{2 \mathrm{~h}_{2}}{\mathrm{~L}}\right) \theta=\frac{\rho \mathrm{c}}{\tau_{\mathrm{eq}}} \theta,
$$

where $h_{1}$ and $h_{2}$ are respectively the heat exchange parameters between the surrounding air and the specimen, and between the grips and the sample. The characteristic time $\tau_{\text {eq }}$ depends on the thermal boundary conditions. The local heat conduction equation becomes

$$
\dot{\theta}+\frac{\theta}{\tau_{\mathrm{eq}}}=\mathrm{S}_{\mathrm{t}}
$$

Let us recall that the mean value per cycle of the temperature is sought. Consequently, the mean heat source has to be evaluated to solve the heat conduction equation. The value of the mean thermoelastic contribution vanishes. The mean heat source reads

$$
\rho c S_{t}=f_{r} D
$$

where $f_{r}$ is the loading frequency, and the mean steady-state temperature $\bar{\theta}$ is the particular solution of the differential equation (21)

$$
\bar{\theta}=\frac{4 \mathrm{f}_{\mathrm{v}} \mathrm{f}_{\mathrm{r}} \tau_{\mathrm{eq}} \sigma_{\mathrm{y}}^{\mu}}{\mathrm{h} \rho \mathrm{c}}\left\langle\Sigma_{0}-\sigma_{\mathrm{y}}^{\mu}\right\rangle .
$$

Equation (23) shows that below $\bar{\Sigma}_{\infty}=\sigma_{\text {y }}^{\mu}$, no temperature variation is observed. Above the latter, a linear response of the temperature as a function of the stress is obtained whose slope $\left(4 \mathrm{f}_{\mathrm{r}} \mathrm{f}_{\mathrm{v}} \tau_{\mathrm{eq}} / \mathrm{h} \rho \mathrm{c}\right) \sigma_{\mathrm{y}}^{\mu}=\eta \mathrm{f}_{\mathrm{v}} \sigma_{\mathrm{y}}^{\mu}$ where $\eta=4 \mathrm{f}_{\mathrm{r}} \tau_{\mathrm{eq}} / \mathrm{h} \rho \mathrm{c}$ is linearly related to the frequency $\mathrm{f}_{\mathrm{r}}$ of the 
cycles. Figure 5 shows the result of the identification of the two parameters $\bar{\Sigma}_{\infty}$ and $\eta f_{v}$ of the model. A good agreement is obtained in accordance with previous results obtained on other materials $[9,12]$. However, it can be noted that the transition defined by a unique threshold $\bar{\Sigma}_{\infty}$ cannot be determined very accurately. An inaccuracy exists on the value the fatigue limit when these measurements are used to determine the mean fatigue limit. This is due to the fact that there is a gradual temperature increase instead of a two-line trend. Yet it allows for a first estimate of a fatigue limit in a very short time duration. As shown in Figure 3, there exists a scatter in fatigue data that needs to be accounted for. The following section deals with an extension of the present approach by considering that the microscopic yield stresses are scattered.

\section{A probabilistic two-scale model}

Let us assume that the microscopic yield stress is a probabilistic variable. An active site (in terms of fatigue mechanism) is defined as an inclusion whose equivalent stress is greater than the microscopic yield stress. These sites are assumed to be described by a Poisson point process [35, 36]. This process is specified by an intensity function $\lambda$ that is assumed to follow a power law of the equivalent stress amplitude $\Sigma$

$$
\lambda(\Sigma)=\frac{1}{\mathrm{~V}_{0}}\left(\frac{\Sigma}{\mathrm{S}_{0}}\right)^{\mathrm{m}}
$$

where $\mathrm{V}_{0} \mathrm{~S}_{0}^{\mathrm{m}}$ and $\mathrm{m}$ are two parameters depending on the material. The probability $\mathrm{P}_{\mathrm{k}}$ of finding $\mathrm{k}$ active sites in a domain $\Omega$ of volume $\mathrm{V}_{\Omega}$ follows a Poisson distribution

$$
\mathrm{P}_{\mathrm{k}}\left(\mathrm{V}_{\Omega}\right)=\exp \left(-\lambda \mathrm{V}_{\Omega}\right) \frac{\left(\lambda \mathrm{V}_{\Omega}\right)^{\mathrm{k}}}{\mathrm{k} !}
$$

and the average number of active sites $\overline{\mathrm{n}}_{\mathrm{a}}$ in a domain $\Omega$ of volume $\mathrm{V}_{\Omega}$ can be related to the intensity of the Poisson process $\lambda$ by

$$
\overline{\mathrm{n}}_{\mathrm{a}}=\lambda(\Sigma) \mathrm{V}_{\Omega}
$$


It follows that the intensity of the Poisson process corresponds to the mean density of active sites for a given applied stress amplitude. This model can be used to describe HCF results. Within the weakest link theory, the failure probability $\mathrm{P}_{\mathrm{F}}$ of a domain $\Omega$ of volume $\mathrm{V}_{\Omega}$ under a homogeneous stress amplitude $\Sigma$ is equal to the probability of finding at least one active inclusion in the volume $\mathrm{V}_{\Omega}$

$$
\mathrm{P}_{\mathrm{F}}=\mathrm{P}_{\mathrm{k} \geq 1}\left(\mathrm{~V}_{\Omega}\right)=1-\exp \left(-\lambda \mathrm{V}_{\Omega}\right)
$$

By using the intensity $\lambda$ defined in Eqn. (24), the failure probability reads

$$
\mathrm{P}_{\mathrm{F}}=1-\exp \left[-\frac{\mathrm{V}_{\Omega}}{\mathrm{V}_{0}}\left(\frac{\Sigma}{\mathrm{S}_{0}}\right)^{m}\right]
$$

Equation (28) corresponds to a Weibull model $[37,38]$ that can be recovered within the framework of a Poisson point process coupled with a weakest link assumption. The parameters of the intensity $\lambda$ (24) then correspond to the Weibull parameters. When the stress field is no longer homogeneous, the previous result can be generalized

$$
\mathrm{P}_{\mathrm{F}}=1-\exp \left[-\frac{\mathrm{V}_{\Omega} \mathrm{H}_{\mathrm{m}}}{\mathrm{V}_{0}}\left(\frac{\Sigma_{F}}{\mathrm{~S}_{0}}\right)^{m}\right]
$$

where $\mathrm{H}_{\mathrm{m}}=\frac{1}{\mathrm{~V}_{\Omega}} \int\left(\frac{\Sigma}{\Sigma_{\mathrm{F}}}\right)^{\mathrm{m}} \mathrm{dV}$ is the stress heterogeneity factor [39] and $\Sigma_{\mathrm{F}}=\max _{\Omega}(\Sigma)$. The effective volume is the product of the loaded volume $V_{\Omega}$ by the stress heterogeneity factor $H_{m}$. The HCF life prediction is often characterized by the mean fatigue limit $\bar{\Sigma}_{\infty}$ and the corresponding variance $\overline{\bar{\Sigma}}_{\infty}^{2}$ that are related to the Weibull parameters $m$ and $V_{0} \sigma_{0}{ }^{m}$ by

$$
\begin{gathered}
\bar{\Sigma}_{\infty}=\mathrm{S}_{0}\left(\frac{\mathrm{V}_{0}}{\mathrm{~V}_{\Omega} \mathrm{H}_{\mathrm{m}}}\right)^{\frac{1}{\mathrm{~m}}} \Gamma\left(1+\frac{1}{\mathrm{~m}}\right) \\
\overline{\bar{\Sigma}}_{\infty}^{2}=\mathrm{S}_{0}^{2}\left(\frac{\mathrm{V}_{0}}{\mathrm{~V}_{\Omega} \mathrm{H}_{\mathrm{m}}}\right)^{\frac{2}{\mathrm{~m}}}\left(\Gamma\left[1+\frac{2}{\mathrm{~m}}\right]-\Gamma^{2}\left[1+\frac{1}{\mathrm{~m}}\right]\right)
\end{gathered}
$$


where $\Gamma(\mathrm{p})=\int_{0}^{\infty} \mathrm{t}^{\mathrm{p}-1} \exp (-\mathrm{t}) \mathrm{dt}$ is the gamma function [40]. These two relationships can be used to evaluate the coefficient of variation

$$
\mathrm{CV}=\frac{\sqrt{\Gamma\left[1+\frac{2}{\mathrm{~m}}\right]-\Gamma^{2}\left[1+\frac{1}{\mathrm{~m}}\right]}}{\Gamma\left(1+\frac{1}{\mathrm{~m}}\right)}
$$

that only depends on the Weibull modulus, i.e., it characterizes the scatter. Equation (30) accounts for scale effects associated to the Weibull model [41]. Namely, the higher the loaded volume, the smaller the mean fatigue limit; the higher the stress heterogeneity (i.e., the smaller $H_{m}$ ), the higher the mean fatigue limit. These coupled effects are described by the introduction of the so-called effective volume $\mathrm{V}_{\text {eff }}=\mathrm{V}_{\Omega} \mathrm{H}_{\mathrm{m}}$ [5]. Consequently corrections are to be performed when comparing data of samples tested in tension/compression to those of structures for which the stress field is different as well as the loaded volume. This analysis is relevant when initiation occurs within the volume as observed for dual-phase steels [22]. Had initiation occurred at or close to the surface, an effective surface instead of an effective volume should have been used.

In the following analysis, the heat transfer analysis is performed again. However, the weakest link hypothesis is not considered since it is assumed that the gradual temperature change is associated with the gradual microplastic dissipation corresponding to a random distribution of yield stresses. The underlying Poisson point process as well as the power law of its intensity are still used. With a Poisson point process, $\frac{\mathrm{d} \lambda}{\mathrm{d} \Sigma} \mathrm{V}_{\Omega} \mathrm{d} \Sigma$ is the mean number of inclusions activated between an equivalent stress $\Sigma$ and $\Sigma+\mathrm{d} \Sigma$ in a domain of volume $\mathrm{V}_{\Omega}$, i.e. the number of sites whose mean fatigue limit lies between $\Sigma$ and $\Sigma+\mathrm{d} \Sigma$, and whose dissipated energy $\mathrm{V}_{\mathrm{RVE}} \mathrm{D}(\Sigma)$ during a load cycle is given by

$$
\mathrm{V}_{\mathrm{RVE}} \mathrm{D}(\Sigma)=\frac{4 \mathrm{~V}_{0}}{\mathrm{~h}} \Sigma\left\langle\Sigma_{0}-\Sigma\right\rangle .
$$


For a specimen of volume $\mathrm{V}_{\Omega}$, the global dissipated energy density $\bar{\Delta}$ for an equivalent stress amplitude $\Sigma_{0}$ during a load cycle is expressed as

$$
\bar{\Delta}=\int_{0}^{\Sigma_{0}} \mathrm{~V}_{\mathrm{RVE}} \mathrm{D}(\Sigma) \frac{\mathrm{d} \lambda}{\mathrm{d} \Sigma} \mathrm{d} \Sigma,
$$

so that

$$
\bar{\Delta}=\frac{4 \mathrm{~V}_{0}}{\mathrm{~h}} \frac{\mathrm{m}}{(\mathrm{m}+1)(\mathrm{m}+2)} \frac{\Sigma_{0}^{\mathrm{m}+2}}{\left(\mathrm{~V}_{0}^{1 / \mathrm{m}} \mathrm{S}_{0}\right)^{\mathrm{m}}}
$$

The change of the mean steady-state temperature is obtained by the resolution of the heat conduction equation (21) by using $\bar{\Delta}$ instead of D

$$
\bar{\theta}=\eta \mathrm{V}_{0} \frac{\mathrm{m}}{(\mathrm{m}+1)(\mathrm{m}+2)} \frac{\Sigma_{0}^{\mathrm{m}+2}}{\left(\mathrm{~V}_{0}^{1 / \mathrm{m}} \mathrm{S}_{0}\right)^{\mathrm{m}}}
$$

Equation (36) does not show a sudden change of the mean steady-state temperature with the stress amplitude but rather a gradual increase in accordance with Fig. 6. The present model is dependent on three parameters, namely, $\eta \mathrm{V}_{0}, \mathrm{~S}_{0}\left(\mathrm{~V}_{0}\right)^{1 / m}$ and $\mathrm{m}$. The influence of the parameters on the change of the steady-state temperature is described in Figs. 6:

- the smaller the scale parameter of the Weibull-model $\mathrm{S}_{0}\left(\mathrm{~V}_{0}\right)^{1 / m}$, the sooner the increase of temperature (Fig. 6a);

- the smaller the scale parameter of the temperature variation $\eta \mathrm{V}_{0}$, the later the increase of temperature (Fig. 6b);

- the smaller the Weibull modulus $\mathrm{m}$, the more gradual the increase of the temperature (Fig. $6 \mathrm{c})$.

The parameters $\mathrm{S}_{0}\left(\mathrm{~V}_{0}\right)^{1 / m}$ and $\eta \mathrm{V}_{0}$ appear simultaneously in the model. Therefore their identification requires two independent measurements, namely temperature measurements and the classical Wöhler $(\mathrm{S} / \mathrm{N})$ curve. 


\section{Identification procedure and predictions}

In the following, the different parameters are identified: namely, $\mathrm{S}_{0}\left(\mathrm{~V}_{0}\right)^{1 / m}$ characterizes the level of the mean fatigue limit for an effective volume equal to $\mathrm{V}_{0}, \eta \mathrm{V}_{0}$ is a parameter depending on material to describe the temperature kinetics, $\mathrm{m}$ measures the scatter of the fatigue limits, and $\mathrm{A}$ characterizes the initiation criterion. First, the parameters A and $\bar{\Sigma}_{\infty}$ are identified by using the classical Wöhler curve and Stromeyer's law

$$
\mathrm{N}=\frac{\mathrm{A}}{\left\langle\Sigma_{0}-\bar{\Sigma}_{\infty}\right\rangle \bar{\Sigma}_{\infty}}
$$

where 15 samples are usually needed. Then the values for $m$ and $\eta V_{0}$ are determined from the analysis of the temperature measurements (Eqn. (36)) for which an additional sample is used. The results of the identification are shown in Fig. 7. The temperature measurements are better described than with the deterministic approach (Fig. 5), especially in the transition regime. The scale parameter $\mathrm{S}_{0}\left(\mathrm{~V}_{0}\right)^{1 / m}$ is obtained by using the expression (30) of the mean fatigue limit for samples with an effective volume equal to $\mathrm{V}_{\text {eff }}=620 \mathrm{~mm}^{3}$ (see Appendix A).

The first validation concerns the prediction of the scatter of the experimental fatigue result in tension/compression (load ratio $\mathrm{R}=-1$ ). The number of cycles to failure is related to the stress amplitude $\Sigma_{0}$ and failure probability by using Stromeyer's law associated to each fatigue limit

$$
\mathrm{N}=\frac{\mathrm{A}}{\left\langle\Sigma_{0}-\Sigma_{\infty}\left(\mathrm{P}_{\mathrm{F}}\right)\right\rangle \Sigma_{\infty}\left(\mathrm{P}_{\mathrm{F}}\right)}
$$

where $\Sigma_{\infty}\left(\mathrm{P}_{\mathrm{F}}\right)$ is the fatigue limit for the failure probability $\mathrm{P}_{\mathrm{F}}$. This limit can be written as

$$
\frac{\ln \left(1-\mathrm{P}_{\mathrm{F}}\right)}{\ln (1-0.5)}=\left[\frac{\Sigma_{\infty}\left(\mathrm{P}_{\mathrm{F}}\right)}{\Sigma_{\infty}(0.5)}\right]^{\mathrm{m}}
$$

by assuming that $\Sigma_{\infty}(0.5)=\bar{\Sigma}_{\infty}\left[\ln (2)^{\frac{1}{\mathrm{~m}}} / \Gamma\left(1+\frac{1}{\mathrm{~m}}\right)\right] \approx \bar{\Sigma}_{\infty}$ (the higher $\mathrm{m}$, the better the approximation). Figure 8 a shows the comparison between the experimental results obtained by 
classical fatigue tests and the prediction of the model for three different failure probabilities. The Wöhler curves can be predicted in a reasonable way.

The second validation concerns the prediction of the Wöhler curve for the same dual-phase steel loaded in alternate bending $(\mathrm{R}=-1)$. It is worth noting that no new parameters are needed to obtain the predictions. Figure $8 \mathrm{~b}$ shows the comparison between the experimental results and the prediction of the model for bending tests $\left(\mathrm{V}_{\mathrm{eff}}=13 \mathrm{~mm}^{3}\right)$. The general trend of the constant failure probabilities is in good agreement with the experimental results and the scatter is reasonably predicted. A Weibull modulus of 20 was identified from the thermal test so that the standard deviation of the fatigue limit is equal to $16.5 \mathrm{MPa}$ by using Eqn. (32) and the value $\bar{\Sigma}_{\infty}=275 \mathrm{MPa}$. Since the effective volume is significantly different (i.e., 30 times smaller) from the axial tension/compression tests, the average fatigue limit in bending is greater than that in axial tension compression. This result is another validation of the probabilistic approach developed herein. For higher stress levels, the predictions become conservative. An explanation may be related to the fact that generalized plasticity occurs in addition to the fact that the propagation stage, which is not described herein, may become more significant.

\section{Conclusions}

The present analysis of the thermal effects during cyclic loadings is related to microplasticity, when the volume of the elasto-plastic inclusions is very small when compared to the volume of the tested sample and when the temperature of the sample can be considered homogenous. If a deterministic model is considered, the mean fatigue limit can be determined by this test. In terms of high cycle fatigue, the same model allows for the identification of a Wöhler curve by using Stromeyer's law.

The probabilistic model presented herein for HCF life predictions is based on a Poisson point distribution of the sites where microplasticity takes place. Within the weakest link theory, the model corresponds to a Weibull law for the fatigue limits. Within the same set of hypotheses, apart from the weakest link assumption, the thermal effects can be described and a gradual change of the 
steady-state temperature with the applied stress amplitude is obtained. The thermal effects are accurately reproduced by the model for a dual-phase steel. In particular, the scatter in HCF can be identified by this test.

A method of identification applicable in HCF is proposed and uses temperature measurements. One sample only is needed to identify the scatter by using temperature measurements and 15 samples to identify the classical Wöhler curve, here described by Stromeyer's law instead of 30 to 50 samples when the scatter in HCF is sought. The failure probability can be predicted by the model for different effective volumes. The validation of the model is obtained for the prediction of $\mathrm{S} / \mathrm{N}$ curves for different effective volumes corresponding to axial and bending fatigue tests.

\section{Acknowledgments}

This work was performed within a collaboration with ARCELOR and Nippon Steel Corporation.

\section{References}

[1] W. Weibull (1961) Fatigue testing and analysing of results. Pergamon Press, Oxford (UK).

[2] A. Brand, J. F. Flavenot, R. Grégoire and C. Tournier (1992) Données technologiques sur la fatigue. Publications CETIM, Senlis (France).

[3] W. Weibull (1949) A statistical representation of fatigue failures in solids. Trans. Roy. Swed. Inst. Tech. 27.

[4] F. Bastenaire (1960) Étude statistique et physique de la dispersion des résistances et des endurances à la fatigue. Thèse d'État, Université de Paris.

[5] D. G. S. Davies (1973) The Statistical Approach to Engineering Design in Ceramics. Proc. Brit. Ceram. Soc. 22, 429-452.

[6] F. Hild, A.-S. Béranger and R. Billardon (1996) Fatigue Failure Maps of Heterogeneous Materials. Mech. Mater. 22, 11-21.

[7] H. Yaacoub Agha, A.-S. Béranger, R. Billardon and F. Hild (1998) High Cycle Fatigue Behaviour of Spheroidal Graphite Cast Iron. Fat. Fract. Eng. Mater. Struct. 21, 287-296.

[8] I. Chantier, V. Denier-Bobet and F. Hild (2000) A Lifing Procedure for Shot-Peened Cast Components Subjected to High Cycle Fatigue. ECF13, CD-ROM, Elsevier, Oxford (UK), (3C.127) 8 p.

[9] M. P. Luong (1992) Infrared thermography of fatigue in metals. SPIE 1682, 222-233.

[10] J.-Y. Bérard, S. Rathery and A.-S. Béranger (1998) Détermination de la limite d'endurance des matériaux par thermographie infrarouge. Mat. Techn. 1-2, 55-57.

[11] J.-C. Krapez, D. Pacou and C. Bertin (1999) Application of lock-in thermography to a rapid evaluation of the fatigue limit in metals. 5th AITA, Int. Workshop on Advanced Infrared Techn. and Appl., Venezia (Italy), Ed. E. Grinzato et al., 379-385.

[12] G. La Rosa and A. Risitano (2000) Thermographic methodology for rapid determination of the fatigue limit of materials and mechanical components. Int. J. Fat. 22 [1], 65-73. 
[13] C. Mabru and A. Chrysochoos (2001) Dissipation et couplages accompagnant la fatigue de matériaux métalliques. Photomécanique 2001, Ed. Y. Berthaud, M. Cottron, J.-C. Dupré, F. Morestin, J.-J. Orteu and V. Valle, GAMAC, 375-382.

[14] A. Galtier, O. Bouaziz and A. Lambert (2002) Influence de la microstructure des aciers sur leurs propriétés mécaniques. Méc. Ind. 3 [5], 457-462.

[15] J. Lemaitre and I. Doghri (1994) Damage 90: a post processor for crack initiation. Comput. Methods Appl. Mech. Engrg. 115, 197-232.

[16] J. Lemaitre, J.-P. Sermage and R. Desmorat (1999) A two scale damage concept applied to fatigue. Int. J. Fract. 97, 67-81.

[17] G. R. Speich and R. L. Miller (1979) Structure and properties of dual phase steels. Ed. R. A. Kot and J. W. Morris, AIME, New York (USA), 146-181.

[18] Z. Li, J. Han, Y. Wang and Z. Kuang (1990) Low-cycle fatigue investigations and numerical simulations on dual phase steel with different microstructures. Fat. Fract. Eng. Mat. Struct. 3 [3], 229-240.

[19] A. Gustavsson and A. Melanger (1994) Variable-amplitude fatigue of a dual-phase sheet steel subjected to prestrain. Int. J. Fat. 16, 503-509.

[20] T. C. Lei, G. Y. Lin and Y. X. Cui (1994) Dislocation substructures in ferrite of plain carbon dual-phase steels after fatigue fracture. Fat. Fract. Eng. Mat. Struct. 17 [4], 451-458.

[21] T. M. Hashimoto and M. S. Pereira (1996) Fatigue life studies in carbon dual-phase steels. Int. J. Fat. 18 [8], 529-533.

[22] K. Nakajima, S. Kamiishi, M. Yokoe and T. Miyata (1999) The influence of microstructural morphology and prestrain on fatigue crack propagation of dual-phase steels in the nearthreshold region. ISIJ International 39 [5], 486-492.

[23] M. Sarwar and R. Priestner (1999) Fatigue crack propagation behaviour in dual phase steel. J. Mat. Eng. Perform. 8, 245-251.

[24] Z. G. Wang and S. H. Ai (1999) Fatigue of martensite-ferrite high strength low alloy dual steels. ISIJ international 39 [8], 747-759.

[25] M. E. Haque and M. S. Sudhakar (2001) ANN based prediction model for fatigue crack growth in DP steel, ". Fat. Fract. Eng. Mat. Struct. 23, 63-68.

[26] A. Chrysochoos and H. Louche (2000) An infrared image processing to analyse the calorific effects accompanying strain localisation. Int. J. Eng. Sci. 38, 1759-1788.

[27] J. Lemaitre and J.-L. Chaboche (1990) Mechanics of Solid Materials. Cambridge University Press, Cambridge (UK).

[28] M. Berveiller and A. Zaoui (1979) An extension of the self-consistent scheme to plastically flowing polycrystals. J. Mech. Phys. Solids 26, 325-344.

[29] E. Kröner (1984) On the plastic deformation of polycristals. Acta Met. 9, 155-161.

[30] J. D. Eshelby (1957) The Determination of the Elastic Field of an Ellipsoidal Inclusion and Related Problems. Proc. Roy. Soc. London A 241, 376-396.

[31] P. Germain, Q. S. Nguyen and P. Suquet (1983) Continuum Thermodynamics. ASME J. Appl. Mech. 50, 1010-1020.

[32] E. Charkaluk, A. Bigonnet, A. Constantinescu and K. Dang Van (2002) Fatigue design of structures under thermomechanical loadings. Fat. Fract. Eng. Mat. Struct. 25 [12], 11991206.

[33] C. E. Stromeyer (1914) The determination of fatigue limits under alternating stress conditions. Proc. Roy. Soc. London A90, 411-425.

[34] A. B. De Vriendt (1987) La transmission de la chaleur. Morin, Québec (Canada).

[35] R. Gulino and S. L. Phoenix (1991) Weibull Strength Statistics for Graphite Fibres Measured from the Break Progression in a Model Graphite/Glass/Epoxy Microcomposite. J. Mater. Sci. 26 [11], 3107-3118.

[36] D. Jeulin (1991) Modèles morphologiques de structures aléatoires et changement d'échelle. Thèse d'État, Université de Caen. 
[37] W. Weibull (1939) A Statistical Theory of the Strength of Materials. Roy. Swed. Inst. Eng. Res., Report 151.

[38] W. Weibull (1951) A Statistical Distribution Function of Wide Applicability. ASME J. Appl. Mech. 18 [3], 293-297.

[39] F. Hild, R. Billardon and D. Marquis (1992) Hétérogénéité des contraintes et rupture des matériaux fragiles. C. R. Acad. Sci. Paris t. 315 [Série II], 1293-1298.

[40] M. Abramowitz and I. A. Stegun (1965) Handbook of Mathematical Functions. Dover Publications, Inc., New York (USA).

[41] W. Weibull (1952) A Survey of 'Statistical Effects' in the Field of Material Failure. Appl. Mech. Rev. 5 [11], 449-451. 


\section{Appendix A: computation of the effective volume}

This appendix aims at detailing the calculation of the effective volume defined by

$$
\mathrm{V}_{\mathrm{eff}}=\mathrm{V}_{\Omega} \mathrm{H}_{\mathrm{m}}
$$

where $\mathrm{H}_{\mathrm{m}}=\frac{1}{\mathrm{~V}_{\Omega}} \int\left(\frac{\Sigma}{\Sigma_{\mathrm{F}}}\right)^{\mathrm{m}} \mathrm{dV}$ is the stress heterogeneity factor and $\Sigma_{\mathrm{F}}=\max _{\Omega}(\Sigma)$. The geometry of tensile and bending samples is defined in Fig. A1. For the tensile test the stress $\Sigma$ depends only on the height $\mathrm{y}$ and the cross-sectional area varies with y as

$$
\mathrm{S}(\mathrm{y})=e \mathrm{l}_{0}\left(1+\frac{2 \mathrm{R}}{\mathrm{l}_{0}}\left(1-\sqrt{1-\left(\frac{\mathrm{y}}{\mathrm{R}}\right)^{2}}\right)\right)
$$

so that the stress heterogeneity factor reads

$$
\mathrm{H}_{\mathrm{m}}=\frac{1}{\mathrm{y}_{0}} \int_{0}^{\mathrm{y}_{0}} \frac{1}{\left(1+\frac{2 \mathrm{R}}{\mathrm{1}_{0}}\left(1-\sqrt{1-\left(\frac{\mathrm{y}}{\mathrm{R}}\right)^{2}}\right)\right)^{\mathrm{m}}} \mathrm{dy}
$$

where $\mathrm{y}_{0}=\sqrt{d(2 R-d)}$.

For the bending test, $\Sigma$ depends on y and $\mathrm{z}$. The dependence with y is calculated as for the tensile test and the dependence with $\mathrm{z}$ is linear. Consequently, when the load ratio is equal to -1 , the stress heterogeneity factor is expressed as

$$
\mathrm{H}_{\mathrm{m}}=\frac{2}{\mathrm{ey}_{0}} \int_{0}^{\mathrm{y}_{0}} \frac{1}{\left(1+\frac{2 \mathrm{R}}{\mathrm{1}_{0}}\left(1-\sqrt{1-\left(\frac{\mathrm{y}}{\mathrm{R}}\right)^{2}}\right)\right)^{\mathrm{m}}} \mathrm{dy} \int_{0}^{\mathrm{e} / 2}\left(\frac{2 z}{e}\right)^{\mathrm{m}} \mathrm{dz}
$$




\section{List of tables}

Table 1: Chemical composition of the DP600 steel $\left(10^{-3} \mathrm{wt} \%\right)$

Table 2: Mechanical properties of the DP600 steel $(\mathrm{Ys}=$ Yield stress, UTS $=$ Ultimate Tensile Strength, $\mathrm{El}=$ Elongation at failure). 
Table 1. Doudard et al.

\begin{tabular}{c|c|c|c|c|c|c}
\hline $\mathrm{C}$ & $\mathrm{Mn}$ & $\mathrm{Si}$ & $\mathrm{Cr}$ & $\mathrm{Ti}$ & $\mathrm{S}$ & $\mathrm{Fe}$ \\
\hline 120 & 1400 & 350 & 200 & 10 & $<5$ & Balance \\
\hline
\end{tabular}

Table 2. Doudard et al.

\begin{tabular}{cccc}
\hline Ys & UTS & Ys / UTS & El \\
\hline$>300 \mathrm{MPa}$ & $>600 \mathrm{MPa}$ & $<0.6$ & $25 \%$ \\
\hline
\end{tabular}




\section{List of figures:}

Figure 1: thermal effects for a dual-phase DP600 steel: -a-cyclic loadings, -b-successive series of 3000 cyclic loadings for different increasing stress amplitudes $\Sigma_{0}$, -c-change of the temperature during 3000 cyclic loadings for the same stress amplitude -d-change of the steady-state mean temperature with the load amplitude.

Figure 2: RVE of the two-scale model.

Figure 3: $\mathrm{S} / \mathrm{N}$ curve of the studied dual-phase steel $\left(\Sigma_{\mathrm{m}}=0\right)$.

Figure 4: analysis of the thermal boundary conditions during the study of the thermal effects for the considered gauge volume.

Figure 5: identification of $\eta$ and $\bar{\Sigma}_{\infty}$ for the studied dual-phase steel $\left(f_{r}=10 \mathrm{~Hz}, \Sigma_{m}=0\right)$.

Figure 6: change of $\bar{\theta}$ with $\Sigma_{0}$ : -a-influence of $\eta \mathrm{V}_{0}$ with $\mathrm{m}=20$ and $\mathrm{S}_{0}\left(\mathrm{~V}_{0}\right)^{1 / \mathrm{m}}=390 \mathrm{MPa} \cdot \mathrm{mm}^{3 / 20}$, -binfluence of $\mathrm{S}_{0}\left(\mathrm{~V}_{0}\right)^{1 / \mathrm{m}}$ with $\mathrm{m}=20$ and $\eta \mathrm{V}_{0}=0.49 \mathrm{~K} \cdot \mathrm{MPa}^{-2}$, -c-influence of $\mathrm{m}$ with $\eta \mathrm{V}_{0}=0.49 \mathrm{~K} \cdot \mathrm{MPa}^{-2}$ and $\mathrm{S}_{0}\left(\mathrm{~V}_{0}\right)^{1 / \mathrm{m}}=390 \mathrm{MPa} \cdot \mathrm{mm}^{3 / 20}$.

Figure 7: identification of $\mathrm{A}$ and $\bar{\Sigma}_{\infty}(-\mathrm{a}-)$ from the classical Wöhler curve, $\eta \mathrm{V}_{0}$ and $\mathrm{m}$ from temperature measurements (-b-) for the studied dual-phase steel $\left(f_{r}=10 \mathrm{~Hz}, \Sigma_{m}=0\right)$. 
Figure 8: comparison between the prediction of the probabilistic model and the experimental results for the studied dual-phase steel $\left(\Sigma_{\mathrm{m}}=0\right)$-a-tensile fatigue test -b-bending fatigue test. The same stress amplitude is shown.

Figure A1: tensile and bending fatigue samples for the studied dual-phase steel with $\mathrm{e}=1.5 \mathrm{~mm}$ (tensile sample: $\mathrm{R}=100 \mathrm{~mm}, 1_{0}=18 \mathrm{~mm}$ and $\mathrm{d}=9 \mathrm{~mm}$; bending sample: $\mathrm{R}=42.5 \mathrm{~mm}, 1_{0}=20 \mathrm{~mm}$ and $\mathrm{d}=5 \mathrm{~mm})$. 


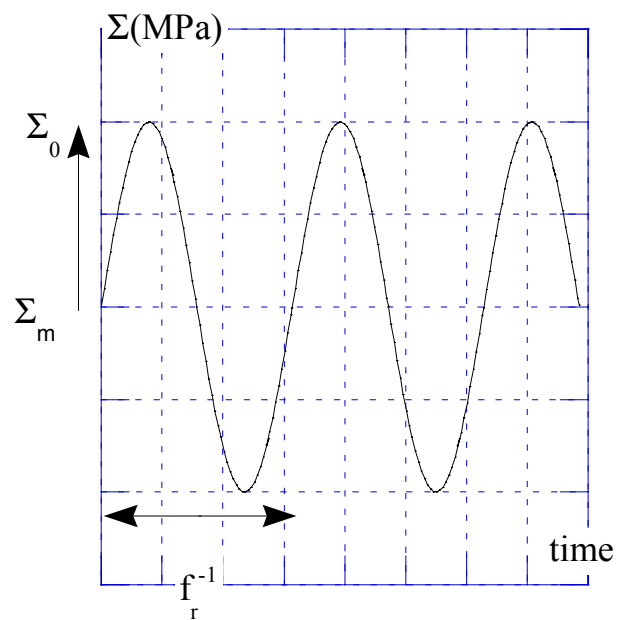

- a -

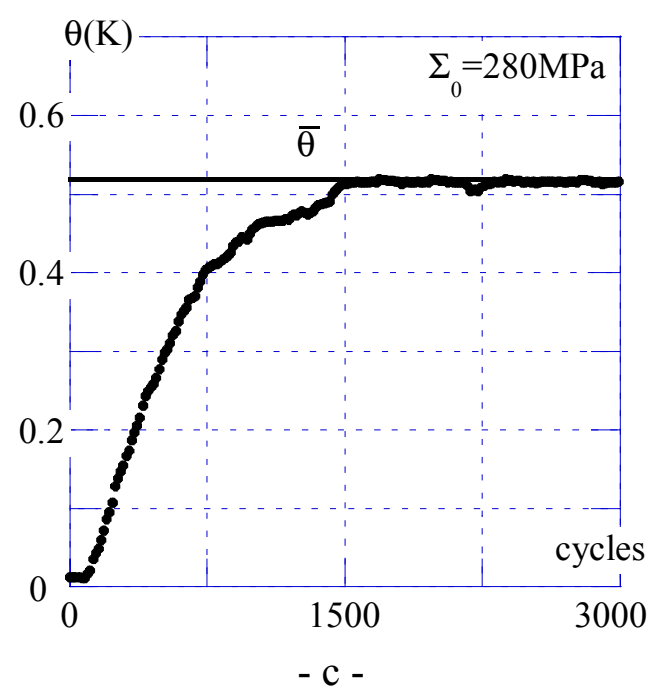

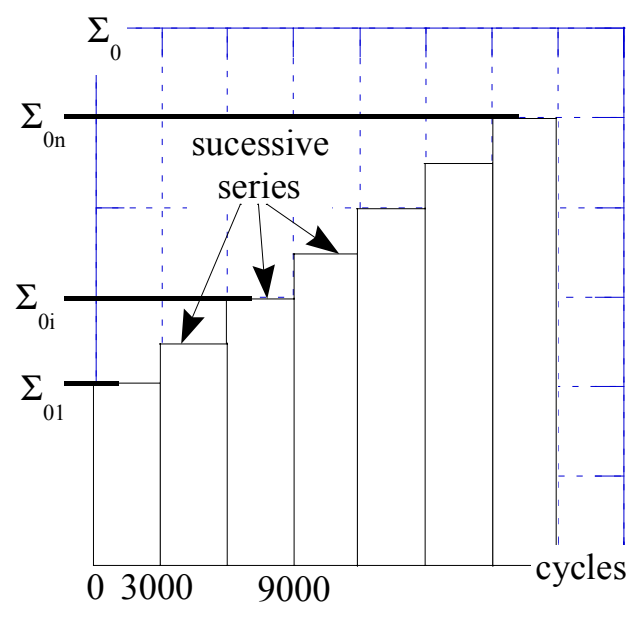

- b -

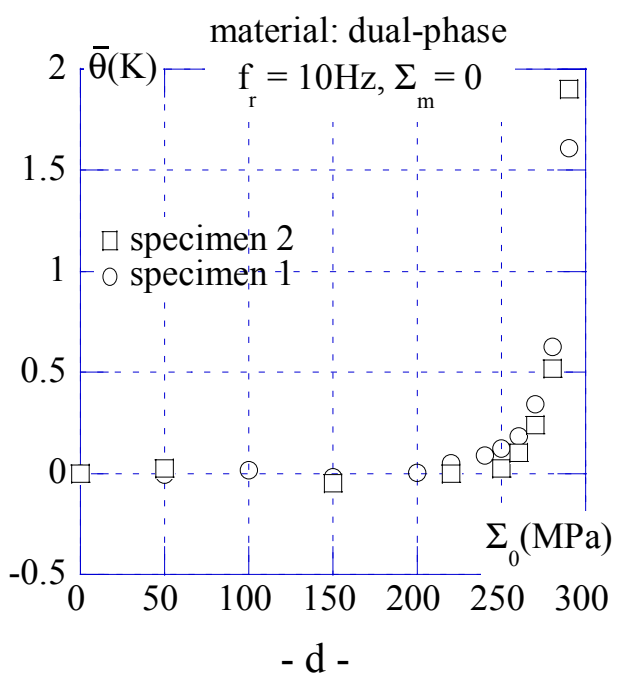

Figure 1. Doudard et al. 


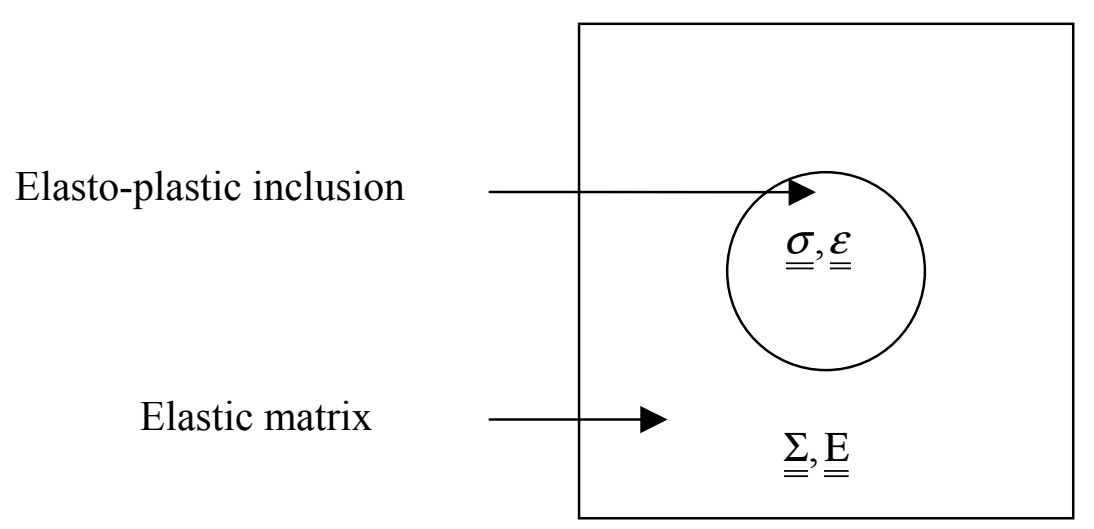

Figure 2. Doudard et al. 


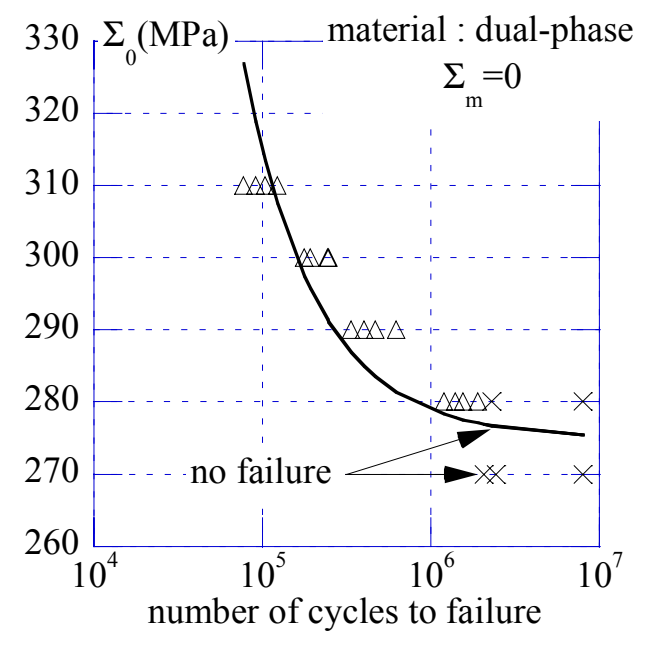

Figure 3. Doudard et al. 

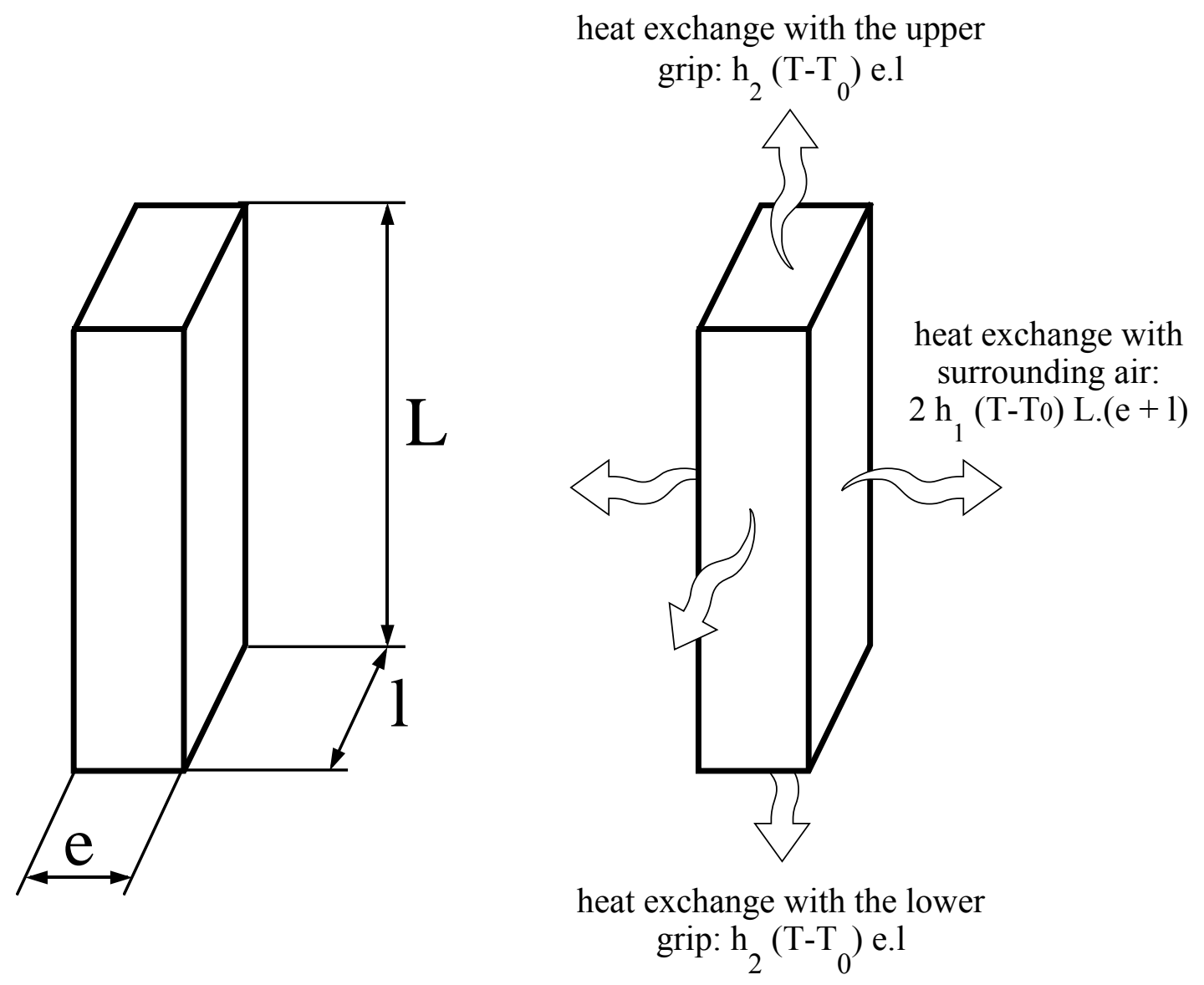

Figure 4. Doudard et al. 


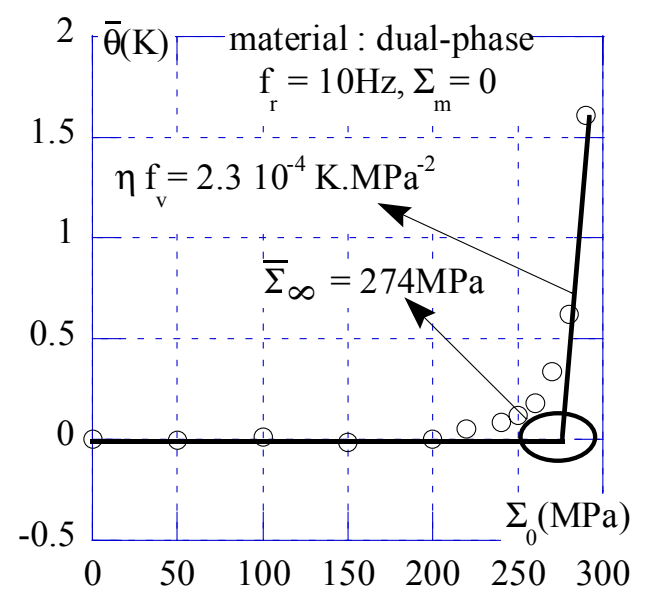

Figure 5. Doudard et al. 


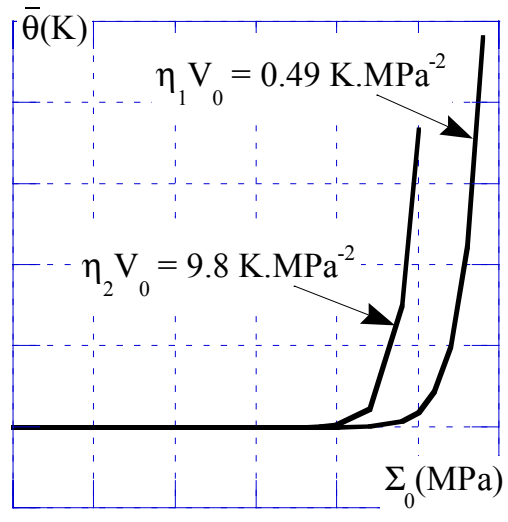

-a-

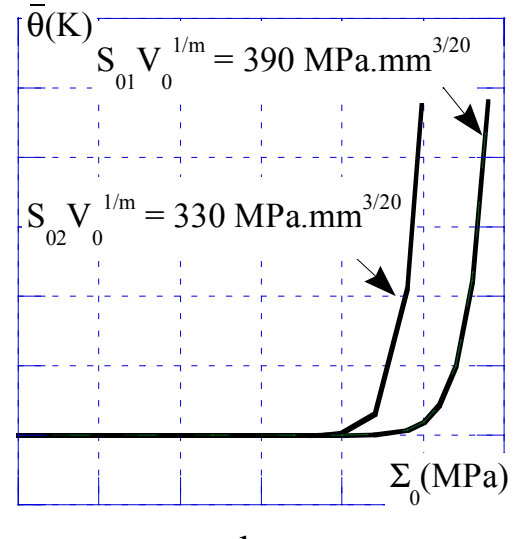

-b-

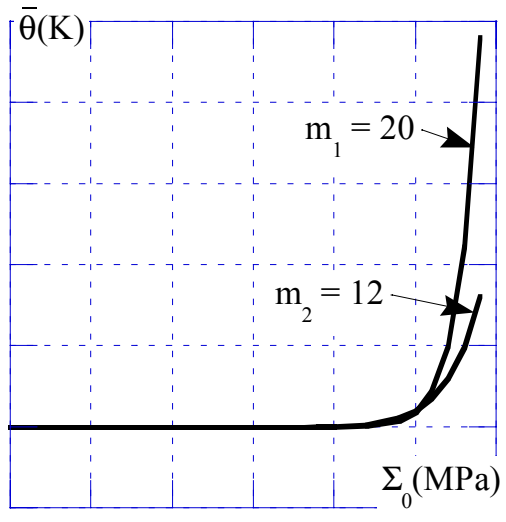

$-c-$

Figure 6. Doudard et al. 


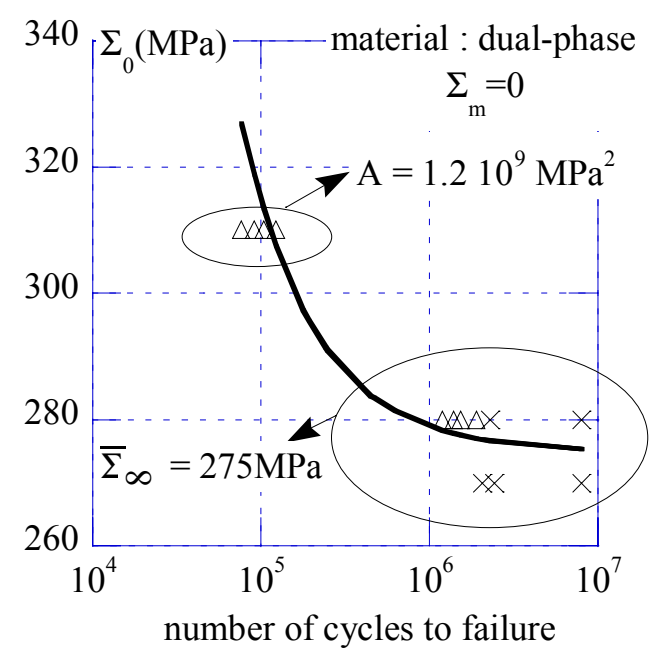

-a-

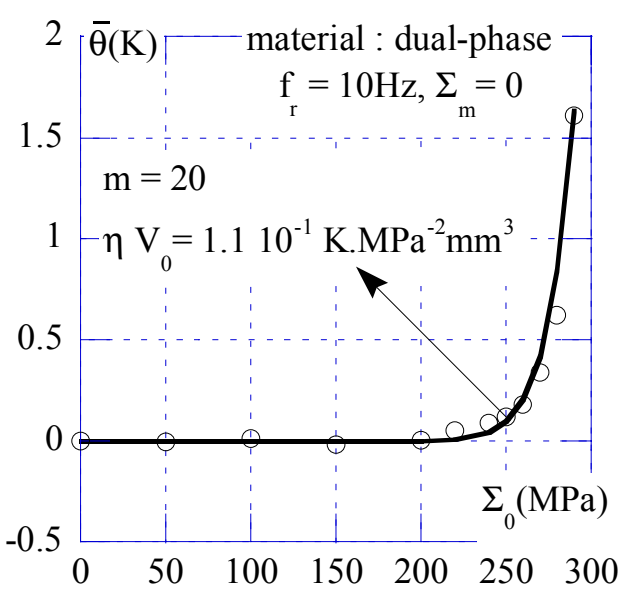

-b-

Figure 7. Doudard et al. 


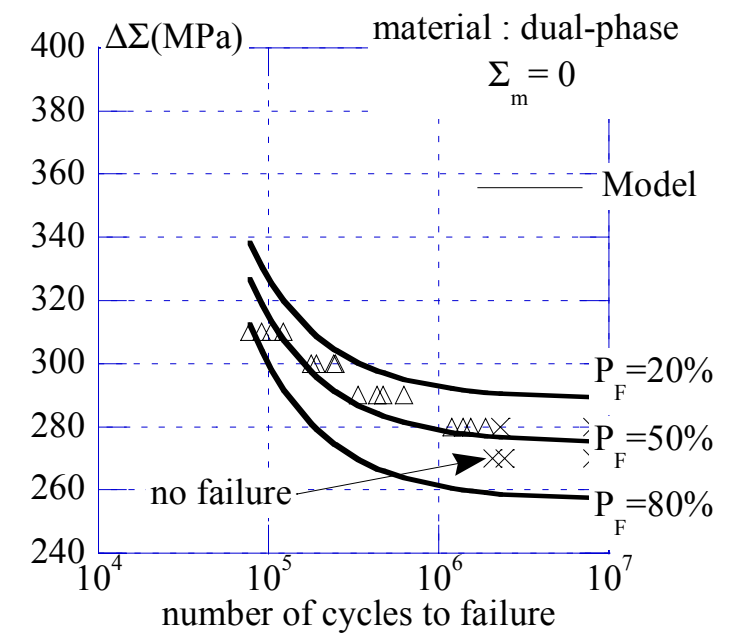

-a-

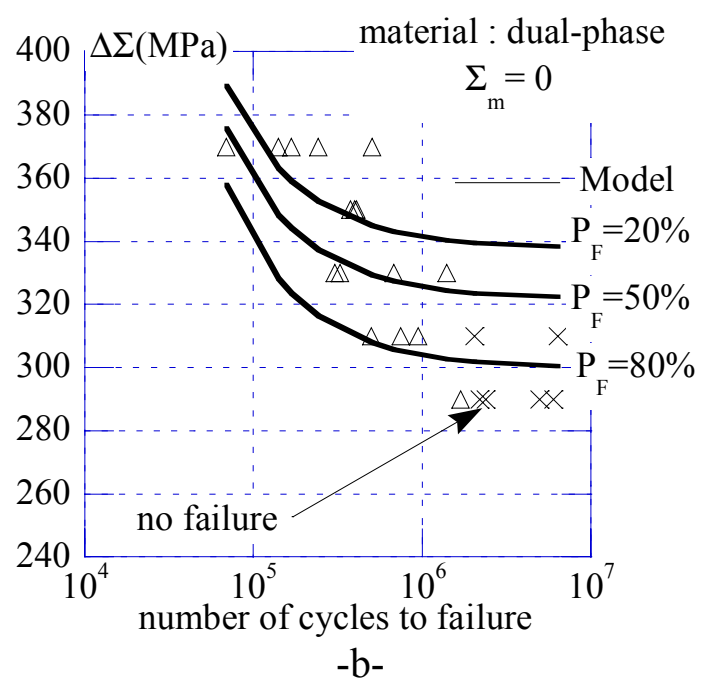

Figure 8. Doudard et al. 


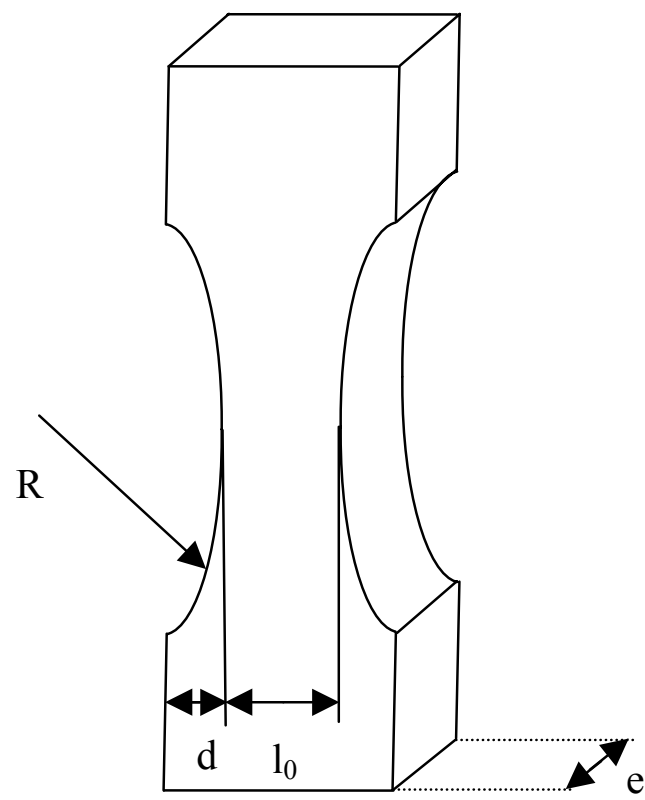

Figure A1. Doudard et al. 